\title{
Lymph Node Involvement
}

National Cancer Institute

\section{Source}

National Cancer Institute. Lymph Node Involvement. NCI Thesaurus. Code C35529.

A finding indicating the spread of cancer to regional or distant lymph node(s). 